\title{
APRENDIZAGEM PARA A SUSTENTABILIDADE ENTRE GESTORES
}

\section{LEARNING FOR SUSTAINABILITY AMONG MANAGERS}

\section{DOI: http://dx.doi.org/10.21714/raunp.v9i2.1128}

\section{Juliana Fabris}

Doutoranda em Administração. Mestre em Administração. Professora da Universidade Comunitária da Região de Chapecó Unochapecó. E-mail: julianafabris@unochapeco.edu.br

\section{Andrezza Aparecida Saraiva Piekas}

Mestre em Administração. Professora da Faculdade Senac/SC. E-mail: andrezzapiekas@gmail.com

\section{Eliane Salete Filippim \\ Pós-doutora em Administração Pública e Governo. Doutora em Engenharia de Produção e Sistemas. Professora e Pesquisadora da Universidade do Oeste de Santa Catarina (Unoesc). E-mail: eliane.filippim@unoesc.edu.br}

\section{Carlos Alberto Barp}

Mestrando em Administração. Universidade do Oeste de Santa Catarina (Unoesc) Chapecó. E-mail: carlos-barp@uol.com.br

Envio em: Abril de 2015

Aceite em: Setembro de 2017

\section{RESUMO}

0 objetivo deste estudo foi investigar como promover a aprendizagem para a sustentabilidade entre gestores, a partir da percepção de representantes da Associação Comercial e Industrial de Chapecó (ACIC), da Câmara de Dirigentes Lojistas (CDL) e do Sindicato do Comércio da Região de Chapecó (SICOM). A abordagem foi descritiva, com enfoque qualitativo, a partir de entrevistas semiestruturadas. Os resultados revelam que há fragilidade na compreensão do tema sustentabilidade, voltada à dimensão econômica e ambiental, com iniciativas incipientes quanto à dimensão social. Quanto à aprendizagem, a percepção dos entrevistados é de que ela ocorre por meio de processo formal atribuído a instituições de educação e ao poder público, o que parece insuficiente para promover a aprendizagem para a sustentabilidade, principalmente no que se refere à interação prática de gestão. Constatou-se ainda que, na visão dos participantes, a aprendizagem deve abranger capacitação, observação, vivência e compartilhamento de experiências, e exige predisposição do aprendente. Por fim, para promover aprendizagem para a sustentabilidade é necessária mudança comportamental e atitudinal, assim como mudança no quadro de referências dos indivíduos.

Palavras-Chave: Aprendizagem Organizacional. Sustentabilidade. Aprendizagem para Sustentabilidade.

\section{ABSTRACT}

The purpose of this study was to investigate how to promote learning for sustainability among managers, based on the perception of representatives of the Commercial and Industrial Association of Chapecó (ACIC), the Chamber of Store Owners (CDL) and the Trade Union of the Region of Chapecó (SICOM). The approach was qualitative, descriptive and based on semi-structured interviews. The main findings of the study show the fragility in the understanding of the sustainability theme, focused on the economic and environmental dimension, with incipient initiatives regarding the social dimension. The interviewees' perception about the learning is that occurs through a formal process assigned to educational institutions and to the public power, which seems insufficient to promote learning for sustainability, especially with regard to the practical interaction of management. Findings also indicated the view of the participants, the learning should encompass training, observation, experience and sharing of experiences, and requires predisposition of the learner. Finally, to promote learning for sustainability are necessary behavioral and attitudinal changes, as well as change in the frame of reference of individuals. 


\section{INTRODUÇÃO}

O crescimento econômico verificado pelas organizações tem sido decorrente do rápido processo de industrialização e avanço tecnológico, marcados pela concorrência em níveis globais. Contudo, nem sempre este crescimento gera desenvolvimento sustentável para a organização e para o conjunto social de seu entorno. É possível que a promoção do desenvolvimento, na sua forma sustentável, careça de amplos esforços de aprendizagem de técnicas, métodos e, sobretudo, comportamentos que demandam investimento de tempo e recursos.

As estratégias voltadas à gestão do conhecimento e aprendizagem organizacional são centrais para as organizações e sua prosperidade. A aprendizagem para a sustentabilidade recomenda a disseminação de cultura organizacional que permita respostas adequadas às necessidades de produtividade combinada com a atenção aos impactos socioeconômicos e ambientais causados pelas organizações.

A aprendizagem organizacional para a sustentabilidade permite interagir e compartilhar práticas coletivas que envolvem múltiplos atores sociais. Ela é suportada por uma estratégia baseada em competências e está ancorada em um modelo de gestão e pela capacidade de articulação nos diversos contextos da sociedade (D'ANGELO; BRUNSTEIN, 2013).

Dentro desta perspectiva da aprendizagem para a sustentabilidade no campo organizacional, este estudo teve, como objetivo geral, investigar como promover a aprendizagem para a sustentabilidade entre gestores, a partir da percepção de representantes da Associação Comercial e Industrial de Chapecó (ACIC), da Câmara de Dirigentes Lojistas (CDL) e do Sindicato do Comércio da Região de Chapecó (SICOM). O estudo se caracteriza, com relação aos fins, como descritivo, com abordagem qualitativa.

A justificativa para a realização do estudo consistiu no interesse dos pesquisadores em verificar qual é a visão dos representantes das entidades sobre os pilares social, econômico e ambiental da sustentabilidade, bem como sua percepção sobre a aprendizagem voltada à sustentabilidade. Justifica-se também a realização desta pesquisa, pelo interesse em observar mais proximamente a questão da aprendizagem transformadora (MEZIROW, 1978; 1981), como enunciada por Closs e Antonello (2014), à medida que apresentam este tipo de aprendizagem como crucial para que o indivíduo se liberte de pressupostos con- dicionantes sobre o mundo e aprenda a pensar por si próprio. Esta autonomia do sujeito parece ser condição para a adoção dos princípios da sustentabilidade na gestão, requerendo a integração entre aprendizagem e sustentabilidade.

Este trabalho está estruturado em cinco seções, incluindo esta. As seções seguintes apresentam o referencial teórico, procedimentos metodológicos, caracterização das entidades empresariais, análise dos resultados e as considerações finais.

\section{APRENDIZAGEM ORGANIZACIONAL, SUSTENTABILIDADE E \\ IMPLICAÇÕES DA APRENDIZAGEM TRANSFORMADORA}

Nesta seção apresenta-se a revisão teórica sobre os temas aprendizagem organizacional, sustentabilidade e implicações da aprendizagem transformadora.

\subsection{APRENDIZAGEM ORGANIZACIONAL}

Os postulados dos indivíduos, ou seja, o conjunto de ideias que constroem sobre o mundo, modelam a forma de agir e a postura diante da vida e do trabalho, exercendo influência na forma como se dá a relação do conhecimento e a aprendizagem dentro das organizações (LEITE, 2014). Assim, o processo de aprendizagem organizacional não pode ser entendido sem antes se compreender como se constitui o conhecimento no indivíduo.

Para Marchese (1997), o conhecimento relevante está associado à experiência ou prática, faz parte de uma determinada atividade, contexto e cultura; e o aprendizado profundo, é requisito para passar do conhecimento à compreensão, bem como, à reformulação dos modelos mentais utilizados para se ver o mundo. A incorporação de conhecimentos significativos é um dos aspectos centrais da aprendizagem, conforme destacam Bastos, Gondim e Loiola (2004, p. 221): "aprender é uma mudança comportamental e atitudinal que envolve os planos afetivo, motor e cognitivo". Nesse sentido, a aprendizagem é um processo longo e complexo.

$\mathrm{O}$ conhecimento adquirido pela aprendizagem pode manifestar-se em mudanças nas cognições ou no comportamento. Incorporado ao contexto da organização, o conhecimento representa um estoque e saber no sentido de um processo e afeta a aprendizagem futura (ARGOTE; MIRON-SPEKTOR, 2011). As 
estruturas de significado delineiam a aprendizagem, decorrem de pressupostos psicoculturais dos indivíduos, moldam as sensações e delimitam percepções, sentimentos e cognição (MEZIROW, 1981).

A aprendizagem organizacional é reconhecida por Salgado e Espíndola (1996) como uma pedra angular na qual se assenta o futuro da organização; com a necessidade de uma visão dialética, pois a organização precisa entender o todo e também reconhecer os indivíduos que a integram e propiciam a atividade organizacional. Os processos de abstração gerados pelos indivíduos são vistos como base da aprendizagem organizacional.

A definição de aprendizagem organizacional varia de acordo com o enfoque adotado (BIDO; FELIX, 2011). A pluralidade de abordagens engloba a psicológica, a sociológica, a cultural, a histórica, a metodológica e a gestão propriamente dita (ANTONELO; GODOY, 2010). No entanto, a essência das definições converge quanto ao aprendizado organizacional como uma mudança no conhecimento da organização, que ocorre à medida que esta adquire experiência (ARGOTE; MIRON-SPEKTOR, 2011). Estes últimos autores destacam que, embora necessária à aprendizagem grupal e organizacional, a aprendizagem individual não é suficiente; o conhecimento adquirido pelo indivíduo deve ser incorporado a um repositório supraindividual para que outros possam acessá-lo.

Quanto à aprendizagem aplicada às organizações, este estudo optou por abordar os processos de aprendizagem transformadora. Para Merizow (1978; 1981; 1997; 2003), a aprendizagem transformadora efetua mudanças no quadro de referências e transforma as perspectivas de significados dos aprendizes, por meio da conscientização e da reflexão crítica, podendo ocorrer em interação grupal ou de forma independente. A conscientização de por que se atribui determinado sentido à realidade é possibilitada pela reflexão crítica, que torna possível libertar-se dos pressupostos condicionantes sobre o mundo e aprender a pensar por si próprio (CLOSS; ANTONELLO, 2014). É nesse sentido que a reflexão crítica é crucial para os indivíduos, para o trabalho, para a cidadania e para a tomada de decisões.

No processo de aprendizagem transformadora, Henderson (2002, p. 203), em revisão aos trabalhos desenvolvidos por Jack Mezirow, Stephen D. Brookfield e Paulo Freire, identificou quatro fases comuns aos três autores:

1. um evento disruptivo ocorre na vida do aprendiz que desafia sua visão do mundo; 2 . $o$ aprendiz então reflete criticamente sobre crenças, pressupostos e valores que moldam a perspectiva atual; 3 . o aprendiz desenvolve uma nova perspectiva para lidar com as discrepâncias surgidas a partir do evento desencadeador; 4. o aprendiz integra a nova perspectiva em sua vida.

A reflexão crítica é destacada por Henderson (2002) como a característica distintiva da aprendizagem transformadora, pois, o aprendiz reflete sobre os próprios pressupostos que sustentam suas opiniões e perspectivas do mundo. Essa reflexão leva a uma mudança fundamental nos modelos mentais, reconhecida pelo aprendiz e por aqueles com os quais interage na vida diária.

Com base na teoria crítica de Jurgen Habermas, Mezirow (1981) postula três domínios de aprendizagem de adultos distintos, mas inter-relacionados, o técnico, o prático e o emancipatório. Esses interesses são fundamentados em diferentes aspectos da existência social (trabalho, interação e poder), com formas e necessidades de aprendizagem distintas.

O domínio de aprendizagem técnica está relacionado à ação instrumental e possibilita dedução de generalizações empíricas de hipóteses legais, com mensuração objetiva. O domínio de aprendizagem prática envolve a interação ou ação comunicativa entre pelo menos dois sujeitos atuantes, sendo necessária a reflexão crítica para a compreensão mútua das intenções. O domínio de aprendizagem emancipatória, por fim, envolve o processo emancipatório de conscientização crítica, que emana do questionamento aos conhecimentos instrumentais e comunicativos do sistema social vigente, em ambientes educacionais formais ou informais e, conduz à aprendizagem transformadora.

Apresentada breve abordagem teórica sobre a aprendizagem organizacional e definida a opção do estudo pela teoria da aprendizagem transformadora, seguem algumas considerações sobre sustentabilidade (especialmente na perspectiva de Amartya Sen e Ignacy Sachs) e as implicações da aprendizagem transformadora.

\subsection{SUSTENTABILIDADE E IMPLICAÇÕES DA APRENDIZAGEM TRANSFORMADORA}

A abordagem da sustentabilidade é ampla e empregada em caráter multidisciplinar, seja na esfera técnica, científica ou política. São profícuas as correntes de pensamento em relação aos enfoques de 
sustentabilidade, bem como, as contradições e ambiguidades do termo (BACHA; SANTOS; SCHAUN, 2010). Em geral, as definições visam integrar viabilidade econômica, cautela ambiental e justiça social, três dimensões conhecidas como triple bottom line (ELKINGTON, 1998; ALMEIDA, 2002). Corrobora Sachs (2008) ao incorporar à sustentabilidade um conjunto da ética e solidariedade com as gerações atuais e futuras.

Rodriguez, Ricart e Sanchez (2002) constataram empiricamente uma problemática: embora a maioria das organizações apresente uma visão de sustentabilidade, esta visão é voltada, quase que exclusivamente, para a questão econômica. Mansourian (2009) chama atenção ao fato de que, ao definir sustentabilidade, muitos autores eliminam a característica holística do termo, o que impede o entendimento integral dos sistemas. Nesses contextos há potencial para a reflexão crítica e aprendizagem transformadora como propulsora da transformação individual e organizacional (HENDERSON, 2002).

Para se alcançar níveis de sustentabilidade é necessário integrar diferentes dimensões como a ética e a solidariedade e, desenvolver processos de aprendizagem que comportem não somente um saber, mas também a escolha qualitativa de como adquirir este saber (MORIN, 1999). No mesmo sentido, o autor afirma que aprender vai além do reconhecer o que virtualmente já era do conhecimento; admite o entrelaçamento do conhecido e desconhecido. Isso vai ao encontro de Mezirow (1981) que entende ser necessário que o aprendiz reveja os pressupostos específicos sobre si mesmo e outros até que a própria estrutura das suposições se transforme.

Para Sachs, Lopes e Dowbor (2010), nos processos de desenvolvimento sustentável, é necessária a evolução do conhecimento. Segundo os autores, a essência do valor de um produto está no conhecimento adquirido e tecnologia incorporada, conhecimentos denominados intangíveis. Nesta seara, a tendência é o conhecimento tornar-se um bem público, decorrente da facilidade de multiplicação que as tecnologias permitem. Um modelo transformador e inovador necessita da colaboração de instituições públicas e privadas, que busquem desenvolver ou compartilhar o conhecimento referente à sustentabilidade, não agredindo a sociedade (indivíduos) e o meio ambiente (CLOSS; ANTONELLO, 2014). Nesse sentido, a aprendizagem referente ao conhecimento se multiplica melhor quando se compartilha, envolvendo múltiplos atores sociais.
A partir de uma fundamentação epistemológica, Sachs (2008) infere que o desenvolvimento está alicerçado em várias dimensões e seu objetivo está direcionado à sincronia das ações éticas e questões sociais. Para o autor, o desenvolvimento tem uma condição explícita voltada ao meio ambiente, direcionada às gerações futuras, na qual o crescimento econômico é caracterizado como necessário e com valor instrumental. Por outro lado, mesmo que o crescimento seja fundamental para que ocorra o desenvolvimento, não é suficiente, tendo-se em vista que o crescimento pode ser excludente, acompanhado das diferenças sociais, pobreza e alto desemprego.

O desenvolvimento, conforme Sen (2010), está relacionado com as melhorias do grau de liberdades que as pessoas conseguem atingir. Ao abordar desenvolvimento como liberdade, descreve cinco espécies de liberdades: "1. liberdades políticas; 2 . facilidades econômicas; 3. oportunidades sociais; 4. garantias de transparências; e, 5. segurança protetora" (SEN, 2010, p. 25). Indica também a necessidade de avanços para as áreas da saúde, educação e direitos civis, complementos primordiais para atingir a liberdade em um contexto mais amplo.

A liberdade é o principal meio (instrumental) e não apenas fim do desenvolvimento (papel constitutivo), pois as oportunidades econômicas, políticas e sociais influenciam diretamente naquilo que as pessoas podem realizar (SEN, 2010). A liberdade de participação é considerada essencial no exercício da democracia e da escolha social responsável. Para se alcançar a liberdade, os processos de aprendizagem transformadora podem se apresentar como condição indispensável, segundo Mezirow (1978), para motivar os aprendizes às ações modificadoras das práticas pessoais, sociais e institucionais.

No campo organizacional há um leque de possibilidades de programas e ações que podem ser implementados pelas organizações para prover o acesso dos trabalhadores e das comunidades do entorno aos insumos que podem gerar qualidade de vida, ampliar as oportunidades sociais e tornar possível à população participar no processo de expansão econômica (SEN, 2010). A aprendizagem, a governança corporativa e a responsabilidade social podem estar integradas na medida em que se estabeleça padrões de conduta da organização para com seus stakeholders (BLACKBURN, 2007). Nesse sentido, é apropriada a discussão sobre o aprendizado da ação, que demonstra como a reflexão e a aprendizagem nos níveis individual e grupal podem promover a aprendizagem 
e mudanças reais em uma organização (HENDERSON, 2002).

Apesar de recente, a aprendizagem transformadora em administração apresenta potencial de exploração das possibilidades (CLOSS; ANTONELLO, 2014), relevante, sobretudo, em experiências organizacionais que tenham como foco uma aprendizagem transformadora para a sustentabilidade, entre outros temas ligados a essa perspectiva.

No tópico seguinte serão expostos os procedimentos metodológicos do estudo.

\section{PROCEDIMENTOS METODOLÓGICOS}

Quanto à abordagem, este estudo classifica-se como qualitativo, pois o foco não foi mensurar resultados numéricos, mas, captar o ponto de vista dos entrevistados, compreendendo a percepção destes sobre o fenômeno estudado. Esta abordagem foi empregada com o intuito de melhor compreender o fenômeno em seu contexto, sendo possível verificar certo grau de subjetividade (GODOY, 2006).

Quanto aos objetivos, a investigação caracteriza-se como descritiva, pois realiza o registro e a interpretação dos fatos sem a interferência do pesquisador, a finalidade é observar, registrar e analisar os fenômenos, sem, contudo, entrar no mérito dos achados (LAKATOS, MARCONI, 2010).

$\mathrm{O}$ estudo iniciou-se a partir de uma pesquisa bibliográfica e, posteriormente, os dados foram coletados de por meio de aplicação de entrevista semiestruturada, com perguntas fechadas e abertas que tiveram como base para a sua formulação as dimensões teóricas e empíricas articuladas neste estudo. Os dados coletados aparecem sob a forma de transcrição integral das entrevistas, de modo a atender o objetivo de conhecer a percepção dos entrevistados sobre como é possível desenvolver a aprendizagem necessária para um gestor de sustentabilidade.

Foram realizadas sete entrevistas, com representantes de cada uma das três entidades, sendo ouvidos presidente, vice-presidente e diretor executivo da ACIC, CDL e SICOM. As entidades empresariais participantes do estudo foram denominadas, Entidade 1; Entidade 2 e Entidade 3. Já os entrevistados, visando a confidencialidade, foram classificados como: E1; E2; E3; E4; E5; E6 e E7.

A seleção das entidades para a aplicação das entrevistas semiestruturadas justifica-se em função da representatividade e similaridade de representação delas no meio empresarial regional. Os dados coletados aparecem sob a forma de transcrição de entrevistas as quais possibilitam maior compreensão do fenômeno estudado. As entrevistas foram gravadas mediante a autorização dos entrevistados.

A análise dos dados qualitativos obtidos por meio das entrevistas foi realizada mediante técnica de análise de conteúdo, que segundo Richardson (2009) possui a interpretação convencional do material. A análise correspondeu às etapas de exploração do material, tratamento dos resultados obtidos, e posterior interpretação, tendo sido realizada cotejando-se os dados coletados a campo com os conceitos apreendidos na revisão de literatura. Quanto aos tópicos de análise foram considerados: a aprendizagem e a sustentabilidade, quanto aos descritores, transformadora (aprendizagem), social, ambiental e econômica (sustentabilidade).

\section{APRESENTAÇÃO DOS RESULTADOS}

Neste tópico apresenta-se breve caracterização das organizações empresariais representadas pelos sujeitos da pesquisa, bem como a descrição e análise dos dados coletados por meio de entrevistas.

\subsection{CARACTERIZAÇÃO DAS ENTIDADES ACIC, CDL E SICOM}

$\mathrm{O}$ funcionamento das três entidades em um mesmo local é percebido como elemento positivo para o setor empresarial regional, no sentido de contribuir para fomentar parcerias e ações na defesa dos interesses do conjunto empresarial que representam. O Quadro 1 apresenta breve resumo das características de cada uma das entidades. 


\section{ASSOCIAÇÃO COMERCIAL E INDUSTRIAL DE CHAPECÓ (ACIC)}

Fundada em 1947, representa os setores da indústria, comércio, prestação de serviços e agronegócio. A estrutura organizacional é composta pelo conselho deliberativo, conselho consultivo, diretoria executiva e equipe de quatorze colaboradores. A entidade atua na tentativa de reduzir as incertezas mercadológicas, oferecendo oportunidades de debate, formação, informação e de intercâmbio que buscam antecipar os cenários, além de manter-se vigilante na defesa dos valores sociais do trabalho e da livre iniciativa, na valorização do empreendedorismo, fundamentado nas liberdades democráticas para a construção de uma sociedade livre, pluralista, justa e solidária (ACIC, 2016).

Câmara de Dirigentes Lojistas de Chapecó (CDL)

Fundada em 1969, representa os lojistas de Chapecó. A estrutura organizacional é composta pelo conselho consultivo, diretoria executiva e equipe de vinte colaboradores. O negócio da CDL é fornecer serviços para a administração do comércio varejista, assim, atua com o objetivo de integrar os associados e instiga-los a participar ativamente das atividades promovidas. As ações da entidade são pensadas para expandir o comércio varejista, promover o associativismo e prestar serviços e informações que permitam a profissionalização empresarial. Diante disso, a entidade tem como visão ser referência na profissionalização e qualificação deste segmento (CDL, 2016).

\section{Sindicato do Comércio da Região de Chapecó (SICOM)}

É uma entidade sindical fundada em 1970, sediada em Chapecó, abrange 25 municípios da região Oeste de Santa Catarina. Objetiva representar e desenvolver o comércio, a partir de serviços e informações, contribuindo para a evolução humana, tecnológica e econômica. A estrutura organizacional é composta pela diretoria executiva, eleita a cada biênio, que contempla os cargos de presidente, vice-presidente, diretor administrativo, diretor financeiro, diretor de relações do trabalho e respectivos diretores adjuntos. Há ainda um conselho fiscal e assessorias administrativa, jurídica e de imprensa. Além de treze colaboradores envolvidos diretamente com as atividades do sindicato. No SICOM funciona também a Comissão Intersindical de Conciliação Prévia (CONCILIA), que é uma comissão conciliadora trabalhista (SICOM, 2016).

Fonte: Elaborado pelos autores (2017)

\subsection{ANÁLISE DOS RESULTADOS}

Na coleta de dados com os representantes das entidades ACIC, CDL e SICOM foram entrevistados os presidentes, vice-presidentes e diretores executivos, totalizando sete entrevistas, com o objetivo de captar a percepção deles acerca de como promover a aprendizagem para a sustentabilidade entre gestores. As entidades serão referidas como Entidade 1 (ACIC), Entidade 2 (CDL) e Entidade 3 (SICOM) e, os entrevistados como E1, E2, etc.

Observa-se que ao saber da entrevista, um dos entrevistados (E3) comentou com os pesquisadores que buscou fazer algumas leituras informativas sobre o tema sustentabilidade e passou a relatar algumas situações identificadas por ele no processo da evolução global das discussões em torno do tema. Pela análise dos dados qualitativos coletados, foi possível constatar que a visão de sustentabilidade, para o E3, é maior que apenas o aspecto ambiental: "o grande desafio do gestor de fazer com que a empresa sobreviva frente ao [...] custo Brasil e ao mesmo tempo tenha a capacidade [...] de produzir [...] evitando [...] deixar para a futura geração um passivo residual muito grande". Entretanto, embora o entrevistado tenha procurado pautar-se pela visão captada em suas leituras, em seus relatos percebeu-se que o maior enfoque de sua percepção acerca de sustentabilidade encontra-se nas dimensões ambiental e econômica.

Quando indagado sobre o seu entendimento de sustentabilidade, o entrevistado E4 ressaltou que "se fala muito e se faz pouco, então ela precisa ser bem planejada, e hoje ainda a gente não tem um plano de sustentabilidade". Para E4, o tema sustentabilidade é importante, tanto que a entidade da qual ele faz parte propôs-se a discuti-lo em Convenção realizada em 2015.

$\mathrm{O}$ entrevistado E3, quando indagado sobre o que entende por sustentabilidade e quais dimensões ela abrange, reconheceu que a sustentabilidade não é apenas ambiental. Destacou, entretanto, a dimensão ambiental como dependente da dimensão econômica, já que, na sua percepção, para as empresas, é uma questão de sobrevivência obter o retorno econômico imediato: "nós temos que ter um lucro imediato, porque senão nós não sobrevivemos, principalmente aqui 
no Brasil" (E3). Nesse sentido, para E3, as tecnologias existentes para reduzir os desperdícios de recursos possuem alto custo o que as tornam inviáveis.

$\mathrm{Na}$ percepção do entrevistado E1, a sustentabilidade envolve "o mínimo de desperdício possivel e o aproveitamento [...] das riquezas naturais [...]", tais como os exemplos por ele citados: formas alternativas de energia renovável, como a solar e o reaproveitamento da água da chuva. Nesse sentido, as afirmações do E1 destacam as dimensões ambiental e econômica da sustentabilidade. Estas abrangem, segundo o entrevistado, reaproveitar e destinar adequadamente os resíduos, utilizar materiais biodegradáveis para limpeza da fábrica e equipamentos, possibilitar a infiltração da água da chuva no solo e, aproveitamento da energia solar. Isso tudo, como forma de contribuir para a sustentabilidade econômica da empresa, valores manifestos pelo entrevistado.

Para o entrevistado E6, a sustentabilidade abrange aspectos internos e externos à organização e "está voltada para manter a empresa funcionando, sendo a dimensão financeira a principal entre elas". Destacou a necessidade das empresas em "manter-se e crescer em um mercado turbulento", sendo que o crescimento econômico possibilitaria aporte para aplicação na sustentabilidade ambiental, segundo ele.

O entrevistado E5 explicitou: "sustentabilidade está classificada em três dimensões, econômica, social e ambiental", entretanto ele destacou que a "importância maior está com a questão ambiental", pois, na visão dele, a sociedade começa a reconhecer as empresas que estão voltadas à preservação ambiental, tratamento de resíduos e redução de poluentes. Abstrai-se deste depoimento, a relação direta percebida entre a dimensão econômica e a dimensão ambiental, sendo a primeira propulsora da segunda. Neste sentido, o E5 acrescentou que "ainda é muito oneroso para as empresas investir nesta área", e observou que a resistência na busca por energias renováveis é resultado da falta de uma política pública de incentivo.

Ainda quanto à dimensão ambiental, foram destacadas, pelo entrevistado E2, algumas ações pontuais promovidas pela Entidade 1 junto à comunidade local, como a coleta e destinação de lixo eletrônico e inspeção veicular: "o núcleo das mecânicas [da ACIC] fez o dia de inspeção veicular [...] e já naquele mesmo dia foi avisado à população que quem tivesse lixo eletrônico levasse até a praça para que fosse feito o destino correto". Do mesmo modo, os entrevistados E1 e E3 destacaram o plantio de mudas de árvores como medida compensatória para a emissão de carbono, geração de lixo e consumo de energia, decorrentes da realização de convenção nacional da Entidade 1, declarando que estiveram: " distribuindo mudas para que as pessoas plantem" (E1).

Quanto às dimensões social e ambiental da sustentabilidade, o entrevistado E4 percebe como economicamente inviável promovê-las. Na sua percepção a dimensão econômica sobrepõe-se a elas, apesar de afirmar ser importante promover [pelo menos] a dimensão ambiental.

Quanto à dimensão social, a percepção do E1 é a de que sua empresa apresenta boas condições de trabalho e higiene. O entrevistado demonstrou também uma atitude benevolente com relação aos trabalhadores. Ressaltou a relevante contribuição do seu papel enquanto empresário, uma vez que mantém um negócio que possibilita o sustento dos empregados e citou que são "100 famílias que dependem de nós". As falas capturadas entre os sujeitos de pesquisa levam a refletir que as iniciativas relacionadas à dimensão social da sustentabilidade ainda são incipientes, não atendendo ainda aquelas que buscam a expansão das liberdades individuais ou a redução da distância entre as camadas sociais (SEN, 2010). Destaca-se a iniciativa do Entrevistado E3, com referência a sua própria empresa: "nós levamos tudo para o Verde Vida, é uma maneira de colaborar com a sustentabilidade e ao mesmo tempo dar certo retorno financeiro para uma entidade beneficente que é o Verde Vida". Nesse sentido, contribui com as dimensões da sustentabilidade ambiental e social, pois a entidade citada pelo E3 é uma Organização Não-Governamental (ONG) que coleta materiais recicláveis e promove o atendimento socioeducativo para adolescentes em situação de vulnerabilidade (VERDE VIDA, 2016).

$\mathrm{O}$ entrevistado E7, indagado sobre sustentabilidade, argumentou que as instituições representativas têm que se reinventar, "servindo de elo para o empresário se reinventar" e ter respostas imediatas para suprir demandas. Para E7, as empresas menores podem ter acesso a novas ferramentas de sustentabilidade por meio do associativismo, de modo a "provocar o novo". Por fim, o entrevistado E1 entende que sustentabilidade é "fazer os reaproveitamentos de tudo que é possivel [...] e a sustentação da própria empresa". E o E4 reconheceu a necessidade de formação e informação quanto ao assunto a todos os associados da entidade a qual pertence.

Em relação à Entidade 1, o entrevistado E2 destacou que "nunca nas nossas reuniões se falou em gestão de sustentabilidade, mas a gente faz a susten- 
tabilidade aplicada de uma forma ou outra no nosso dia-a-dia." Com vistas a ampliar a atuação sustentável das empresas, o E2 percebe que um gestor de sustentabilidade teria atuação mais abrangente: "se nós tivéssemos dentro da empresa um gestor de sustentabilidade, iria ser bem diferente [...], focado só nisso, poderia ser feito muito mais". Entretanto, o entrevistado E1 se contrapõem função do ônus financeiro que isso geraria. Nesse sentido, o entrevistado E2 complementou que o gestor de sustentabilidade seria aplicável a uma grande empresa, em função do ônus financeiro incompatível com negócios menores. A percepção também foi referida por E3, que acredita que tão breve não deve se firmar, como uma realidade em empresas brasileiras, o gestor de sustentabilidade, salvo nas grandes organizações. Ele também remeteu para o poder público a responsabilidade por incentivar a formação em sustentabilidade.

As observações feitas por E3 são no sentido de que o gestor de sustentabilidade é um cargo específico na empresa. Entretanto, o que a literatura aponta é a necessidade de que esta seja uma postura de gestão. Indagados sobre as características desejáveis a um gestor de sustentabilidade, o entrevistado E1 afirmou que "tem que ter um espírito de reaproveitamento". Para o entrevistado E2, o gestor "não pode ser um ecochato; tem que enxergar oportunidades". As afirmações coletadas foram mais no sentido de que o gestor de sustentabilidade perceba formas de contribuir com a sustentabilidade, especialmente na sua dimensão ambiental e que, sobretudo, isso retorne em benefícios financeiros para a empresa.

$\mathrm{O}$ entrevistado E3 considera que os empresários e profissionais com formação técnica tem maior capacidade intelectual e maior facilidade para compreender o processo de sustentabilidade, o que revela a concepção de que a aprendizagem se processa por meios formais e pode levar a excluir indivíduos com baixa escolaridade. Essa afirmação, no entanto, vem de encontro à afirmação exposta por Closs e Antonello (2014), de que a aprendizagem transformadora se volta à educação de adultos em contextos formais e informais e considera a interseção entre as dimensões individual e social, pois os indivíduos vivem em sociedade.

Já na fala do entrevistado E3, percebe-se um sentimento de impotência quanto a "o quê" e "como" realizar ações sustentáveis, bem como, um apelo para que alguém forme gestores de sustentabilidade, uma vez que, na percepção dele, os empresários já fazem o possível:
[...] gestor de sustentabilidade [...] é uma profissão [...] que vai se expandir [...] direcionem ao gestor de sustentabilidade, por favor! Formem profissionais nesta área, porque o que nós empresários fazemos hoje empiricamente, vamos tateando e vamos vendo o que é possível fazer [...]. Nós queremos fazer muito mais, mas não podemos.

Outro ponto destacado na percepção do entrevistado E3, é que as pessoas só se preocupam com práticas sustentáveis se isso tiver reflexo financeiro que lhe seja diretamente atribuível.

Ainda sobre as características desejáveis ao gestor de sustentabilidade, para o entrevistado E4, de modo geral, "precisa ser uma pessoa correta e com perfil ético". Este entrevistado trouxe à tona elementos comportamentais que vão além da formação acadêmica, mais afetos à aprendizagem transformadora. Já na percepção de E5, são indispensáveis características como, "formação, experiência, conhecimento prático e flexibilidade para mudanças drásticas". Para o entrevistado E3, quanto às características de um gestor de sustentabilidade, "ele tem que ter aquele despertar, aquela vontade de ser ecologicamente correto; às vezes só o empresário não pode, embora queira fazer, porque o empresário olha muito para o lucro". Nesse mesmo sentido E3 prosseguiu sua fala e destacou que "o gestor ambiental, tem que procurar interagir com o todo, com seus comandados e inclusive com seus fornecedores", no sentido de que as partes envolvidas tenham responsabilidade por recuperar o ambiente degradado.

Quando indagado sobre as características que considera necessárias para um gestor de sustentabilidade, o entrevistado E6 afirmou: "A primeira ele tem que ter treinamento, tem que ter acesso à informação e tem que estar disposto a ter essa informação". Ressaltou ainda que é possível despertar o interesse demonstrando que existem oportunidades e formas diferentes de se fazer. Entretanto, cabe a cada indivíduo se responsabilizar por querer, ou não, aprender. Portanto, percebe-se que a aprendizagem deve ser ativa, já que os indivíduos passam a desempenhar papel ativo e de grande influência na busca do conhecimento (SOUZA; VERDINELLI, 2014).

No mesmo sentido, o entrevistado E7, destacou que é possível criar uma cultura na organização, traduzindo a sustentabilidade no dia a dia, de forma a desenvolver lideranças, por meio da capacitação profissional. Dessa forma, quando indagado a respeito de como se promove a aprendizagem em um gestor de 
sustentabilidade, o entrevistado E6 afirmou: "quando a gente dá exemplo começa despertar um pouquinho cada um. As pessoas começam: bom, se eles fizeram, então, também eu posso fazer.". Esta percepção vai na linha de que, a partir da aprendizagem significativa, os conceitos são ampliados, organizados e diferenciados em função do compartilhamento do conhecimento (MOREIRA; MASINI, 1982).

Entretanto, a aprendizagem é percebida como integrante de um processo formal para o entrevistado E2, quando afirmou: "Então aí vem o meio acadêmico pra fazer essa pessoa, pra fazer essa convergência ai". O entrevistado explicitou seu entendimento de que a aprendizagem se dá formalmente e é de responsabilidade de uma instituição de ensino, do meio acadêmico, do professor. No mesmo sentido, E3 declarou que entende que a aprendizagem se dá de maneira formal, em universidades, instituições de ensino, e que deve ser incentivada pelo poder público. O E3 disse também que acredita que devem surgir em breve cursos de gestor de sustentabilidade que serão demandados em função da boa remuneração e de perspectivas de empregabilidade. Novamente se observa que, apesar de considerarem relevante, alguns entrevistados tendem a atribuir o desenvolvimento de gestores de sustentabilidade a outros atores, menos a si ou às entidades que representam.

Quanto à aprendizagem para a sustentabilidade, o entrevistado E1 destacou que, para uma mudança de perspectiva, é necessário treinamento, por meio do qual haja a conscientização dos empresários de que "eles estão contribuindo para eles próprios e para a própria empresa, e para a natureza". Ressalta a necessidade de entendimento e mudança de postura do empresário. Isso vai ao encontro da aprendizagem transformadora, no sentido de que é necessário mudar o quadro de referências dos indivíduos (CLOSS; ANTONELLO, 2014), resta saber se para este fim o treinamento seria suficiente para promover aprendizagem transformadora.

Para o entrevistado E1 a aprendizagem é uma "vivência em casa, na empresa, no setor acadêmico, de uma maneira geral". Nesse contexto, enquadra-se a aprendizagem ativa, pois o indivíduo passa a desempenhar papel ativo e de grande influência na busca do conhecimento e deixa de ser uma pessoa passiva, exposta ao conhecimento (SOUZA; VERDINELLI, 2014).

Ainda com relação às formas de aprendizagem para um gestor de sustentabilidade, o entrevistado E1 afirmou: "quando bate na necessidade, é que se vê como se economizar e fazer pra aproveitar". Atesta essa percepção o entrevistado E3 ao afirmar que: "os maiores avanços que o mundo tem é a partir das grandes tragédias [...]. Os governos mudam de direção, e os grandes avanços tecnológicos sentidos se dão [...] em cima dessas tragédias". A percepção do entrevistado leva a refletir sobre as fases da aprendizagem transformadora, que desafiam a visão de mundo do aprendiz, de modo a fazê-lo refletir criticamente sobre seus pressupostos, desenvolver novas perspectivas e integrá-las em sua vida (CLOSS; ANTONELLO, 2014).

Na percepção do entrevistado E7, a universidade mostra-se fragilizada para promover a aprendizagem para a sustentabilidade, principalmente no que se refere à interação prática do profissional. Ainda, ressaltou o E7, que a formação passa pelo interesse pela aprendizagem, mudança de cultura do empresário, programas permanentes de capacitação, fóruns de aprendizagem compartilhando experiências, coaching, bibliotecas de casos de sucessos, novas propostas pedagógicas. Dessa forma, para E7, o gestor deve ser instigado à pró-atividade. Nesse sentido, a aprendizagem ativa sustenta a premissa de que a aprendizagem ocorra pelo exercício ou prática (MASETTO, 2011). Do mesmo modo, ocorre aprendizagem significativa quando as informações e ideias novas caracterizam uma coerência em sua composição, se relacionam com definições abrangentes, evidentes e relacionadas à disposição do conhecimento e contribuem para a diferenciação, ordenação e equilíbrio (MOREIRA; MASINI, 1982).

Quanto à percepção dos entrevistados sobre sustentabilidade e suas dimensões, observou-se que há uma fragilidade na compreensão do tema. Dos sete entrevistados, seis mencionaram expressamente apenas as dimensões econômica e ambiental. Para os entrevistados, a dimensão ambiental depende da dimensão econômica. Consideram que é uma questão de sobrevivência o retorno econômico imediato. Entendem ainda, que o crescimento econômico possibilita aporte para aplicação na dimensão ambiental.

No tocante a dimensão social, para os entrevistados, não se pode inferir a percepção de que a promoção do desenvolvimento humano influencia nas habilidades produtivas das pessoas e, portanto, reflete no crescimento econômico. Do mesmo modo, são incipientes as iniciativas relacionadas aos aspectos abrangentes de sustentabilidade social, como por exemplo, os que buscam a expansão das liberdades individuais ou a redução da distância entre as cama- 
das sociais (SEN, 2010).

Quanto às características desejáveis a um gestor de sustentabilidade, os entrevistados são unanimes em reconhecer a necessidade de formação e informação quanto ao tema. Sobressaem-se as características formação, experiência, flexibilidade, ética, interação, empatia, dinamismo, visão holística e empenho.

Com base na indagação de como se aprende a ser um gestor de sustentabilidade, torna-se explícito o entendimento dos entrevistados de que a aprendizagem se dá formalmente, é de responsabilidade de instituições de ensino e deve ser incentivada pelo poder público. Ainda quanto às formas de aprendizagem, destacam-se o interesse do indivíduo, o compartilhamento de experiências, a vivência, a observação, a capacitação permanente e situações traumáticas. Destacou-se no estudo a percepção de que a academia se mostra fragilizada para promover a aprendizagem para a sustentabilidade, principalmente no que se refere à interação prática do profissional.

Nesse sentido, conclui-se pela necessidade de formação, conscientização, envolvimento e visão holística do gestor, do que decorre uma mudança de postura para que haja aprendizagem para a sustentabilidade. Assim, sustenta-se a premissa de que a aprendizagem ativa ocorre pelo exercício ou prática, atividades formuladas de tal forma que há efetividade no aprendizado (MASETTO, 2011).

Da mesma forma, a incorporação de conhecimentos significativos é um dos aspectos centrais da aprendizagem, cujo processo é longo, complexo e envolve mudança comportamental e atitudinal (LEITE, 2014). Nesse sentido, pode-se integrar às fases da aprendizagem transformadora, que desafiam a visão de mundo do aprendiz, de modo a fazê-lo refletir criticamente sobre seus pressupostos, desenvolver novas perspectivas e integrá-las em sua vida (CLOSS; ANTONELLO, 2014).

\section{CONSIDERAÇÕES FINAIS}

O estudo teve como objetivo geral foi investigar como promover a aprendizagem para a sustentabilidade entre gestores, a partir da percepção de representantes da Associação Comercial e Industrial de
Chapecó (ACIC), da Câmara de Dirigentes Lojistas (CDL) e do Sindicato do Comércio da Região de Chapecó (SICOM). Inicialmente efetuou-se uma revisão bibliográfica que abordou a aprendizagem organizacional, sustentabilidade e implicações da aprendizagem transformadora. Na sequência indagaram-se aos representantes das entidades ACIC, CDL e SICOM acerca de sua percepção sobre sustentabilidade e suas dimensões, sobre as características desejáveis a um gestor de sustentabilidade e como se aprende a ser um gestor de sustentabilidade.

Apesar das falas remeterem principalmente à questão ambiental, na visão dos entrevistados, a sustentabilidade tende para a dimensão econômica, uma vez que os entrevistados valorizam prioritariamente os resultados financeiros que suas organizações podem obter pela atividade empresarial. . Quanto à dimensão social, foi enfatizada por apenas um dos depoentes. Verificou-se desse modo que as dimensões econômica, social e ambiental não são percebidas de forma equilibrada e nem na mesma proporção, como relevantes pelos sujeitos ouvidos. Eles também tendem a remeter as iniciativas pela educação em sustentabilidade para a esfera pública, retirando de si responsabilidade na promoção deste tipo de aprendizagem.

Quanto à aprendizagem, na percepção dos entrevistados, um gestor voltado à sustentabilidade deve passar por um processo formal de capacitação, que deve ficar a cargo de instituições de ensino e do poder público, e ser voltado à atuação prático do profissional. Não foram coletadas evidências entre os entrevistados da relevância da reflexão teórica para a aprendizagem de gestores em sustentabilidade. Destacaram ainda os depoentes, que os programas de aprendizagem devem abranger vivências e compartilhamento de experiências.

Por fim, este trabalho não pretende exaurir o tema, já que apresenta algumas limitações, como o fato da impossibilidade de generalização dos resultados. Assim, são sugeridas novas investigações, em diferentes contextos organizacionais, para captar como se dá a compreensão sobre o tema da sustentabilidade, bem como sobre as formas de aprendizagem e sua relevância entre gestores. 
ALMEIDA, F. O bom negócio da sustentabilidade. Rio de Janeiro: Nova Fronteira, 2002.

ANTONELLO, C. S.; GODOY, A. S. A encruzilhada da Aprendizagem Organizacional: uma visão multiparadigmática. Revista de Administração Contemporânea, Curitiba, v. 14, n. 2, p. 310-332, 2010.

ARGOTE, L.; MIRON-SPEKTOR, E. Organizational learning: From experience to knowledge. Organization Science, v. 22, n. 5, p. 1123-1137, 2011.

ASSOCIAÇÃO COMERCIAL E INDUSTRIAL DE CHAPECÓ (ACIC). Institucional. Disponível em: $<$ http://www.acichapeco.com.br/institucional>. Acesso em: 09 out. 2014.

BACHA, M. L.; SANTOS, J.; SCHAUN, A. Considerações teóricas sobre o conceito de sustentabilidade. Simpósio de Excelência em Gestão e Tecnologia- SEGeT, 7, 2010. Anais... Resende: SEGeT, 2010.

BASTOS, A. V. B; GONDIM, S. M. G; LOIOLA, E. Aprendizagem organizacional versus organizações que aprendem: características e desafios que cercam essas duas abordagens de pesquisa. Revista de Administração, São Paulo, v. 39, n.3, p. 220-230. Jul./ago./set., 2004.

BLACKBURN, W. R.; The sustainability handbook: the complete management guide to achieve social, economic and environmental responsibility. London: Earthscan, 2007. Charper 3.

BIDO, S.; FELIX, B. Comparação de três escalas para a mensuração da Aprendizagem Organizacional. In: Encontro da ANPAD (ENANPAD), 35., 2011, Rio de Janeiro. Anais... Rio de Janeiro: ANPAD, 2011. p. 1-17.

CDL, Câmara de Dirigentes Lojistas. A CDL Chapecó. Disponível em: $<$ http://www.cdlchapeco.com.br/a-cdlchapeco>. Acesso em: 09 out. 2016.

CLOSS, L. Q.; ANTONELLO, C. S. Teoria da aprendizagem transformadora: contribuições para uma educação gerencial voltada para a sustentabilidade. RAM. Revista de Administração Mackenzie, v. 15, n. 3, p. 221-252, 2014.

D'ANGELO, M. J.; BRUNSTEIN, J. Aprendizagem social para a sustentabilidade: Um estudo sobre negócios sustentáveis em contextos de múltiplos atores sociais, relações e interesses. Encontro da Associação Nacional de Pesquisa Pós-Graduação em Administração, 27, 2013.

ELKINGTON, J. Cannibals with forks - Triple bottom line of 21st century business. Stoney Creek, CT: New Society Publishers, 1997.

GODOY, A. S. Refletindo sobre critérios de qualidade da pesquisa qualitativa. Revista Eletrônica de Gestão Organizacional (Gestão.Org), v. 3, n. 2, mai./ago. 2005.

HENDERSON, G. M. Transformative learning as a condition for transformational change in organizations. Human Resource Development Review, v. 1, n. 2, p. 186-214, 2002.

MANSOURIAN, S. Sustainability Partnerships. The Manages Handbook. Switzerland: Palgrave, Mcmillan, 2009. Charper 2.

LAKATOS, E. M.; MARCONI, M. A. Técnicas de pesquisa.7. ed. São Paulo: Atlas, 2010.

LEITE, L. M. F. S. Um estudo de caso sobre aprendizagem organizacional. 2014. Dissertação de Mestrado. 
Disponível em: <http://bibliotecadigital.fgv.br/dspace/handle/10438/11824>. Acesso em: 14 ago 2017.

MARCHESE, T. J. The new conversations about learning: insights from Neuroscience and Anthropology Cognitive Science and work place studies. Washington: AAHE Publication, 1997.

MASETTO, M. T. Inovação curricular no ensino superior. Revista Científica e-curriculum, v. 7, n. 2, 2011.

MEZIROW, J. Perspective transformation. Adult education, v. 28, n. 2, p. 100-110, 1978.

, J. A critical theory of adult learning and education. Adult education, v. 32, n. 1, p. 3-24, 1981.

, J. Transformative learning: Theory to practice. New directions for adult and continuing education, v. 1997, n. 74 , p. $5-12,1997$.

2003.

, Transformative learning as discourse. Journal of transformative education, v. 1, n. 1, p. 58-63,

MOREIRA, M. A.; MASINI, E. F. S. Aprendizagem significativa: a teoria de David Ausubel / Marco A. Moreira, Elcie F. Salzano Masini. São Paulo: Moraes, 1982.

MORIN, Edgar. O método 3: a consciência da consciência (tradução de Juremir Machado da Silva). Porto Alegre: Sulina, 1999.

REY, F. G. Pesquisa qualitativa e subjetividade: os processos de construção da informação. 1.ed. São Paulo: Thomson, 2005. V. 1.

RICHARDSON, R. J. Pesquisa social: métodos e técnicas. 3. ed. São Paulo: Atlas, 2009.

RODRIGUEZ, M. A.; RICART, J. E.; SANCHEZ, P. Sustainable development and the sustainability of competitive advantage: A dynamic and sustainable view of the firm. Creativity and Innovation Management, v. 11, n. 3, p. 135-146, 2002.

SACHS, I. Desenvolvimento: includente, sustentável, sustentado. Rio de Janeiro: Garamond, 2008.

SACHS, I; LOPES, C.; DOWBOR, L. Crises e oportunidades em tempos de mudança. Documento de referência para as atividades do núcleo Crises e Oportunidades no Fórum Social Mundial Temático - Bahia. Bahia, 2010. Disponível em: <http://www.scielo.gpeari.mctes.pt/pdf/egg/v15n1/v15n1a08.pdf.>. Acesso em: 20 ago. 2017.

SALGADO, C. M.; ESPÍNDOLA, M. T. E. El aprendizaje organizacional: el estado del arte hacia el tercer milenio. Revista Gestión y estrategia, n. 10, p. 60-72, 1996.

SEN, A. Desenvolvimento como liberdade (tradução de Laura Teixeira Motta; revisão técnica Ricardo Dominelli Mendes). São Paulo: Companhia das Letras, 2010.

SICOM, Sindicato do Comércio da Região de Chapecó. Sobre o SICOM. Disponível em: $<$ http://sicom.com. br/ >. Acesso em: 09 out. 2016.

SOUZA, N. R.; VERDINELLI, M. A. Aprendizagem ativa em administração: Um estudo da aprendizagem baseada em problemas (PBL) na graduação. Revista Pretexto, v. 15, n. NE, p. 29-47, 2014.

VERDE VIDA. Conheça o Verde Vida: o que é. Disponível em: <http://www.verdevida.org.br/>. Acesso em: 24 nov. 2016.

YIN, R. K. Estudo de caso: planejamento e métodos. 5. ed. Porto Alegre: Bookman, 2010. 